\title{
An Analysis of Hall's Theory of Cultural Identity and Its Application in Flipped Class
}

\author{
Bo Yang ${ }^{1, *}$ Dan Zhao ${ }^{1}$ Lu Liu $^{1}$ \\ ${ }^{1}$ East University of Heilongjiang, Harbin, Heilongjiang, China \\ *Corresponding author. Email: 28172710@QQ.com
}

\begin{abstract}
This paper understands Hall's "cultural identity theory" through the cultural phenomenon in the ethnic dense. Through the study of the connotation, definition, characteristics and construction mode of "cultural identity theory", the author understands and digests this theory further, and through the reflection of this theory, the author put it into the actual teaching, combined with cross-cultural teaching, hoping to understand the definition of cross-cultural identity.
\end{abstract}

Keywords: Hall, Cultural identity theory, Ethnic dispersion, Cross-cultural teaching.

\section{INTRODUCTION: THE DEFINITION AND CONNOTATION OF HALL'S THEORY OF CULTURAL IDENTITY}

Worldwide, the issue of cultural identity has a long history, dating back to some previous colonial activities. Around the 1950s, globalization around the world led to more and more frequent exchanges between countries, so the issue of cultural identity has been further concerned by scholars. In the late 1990s, globalization brought about a great impact of homogenization on third world culture, so most scholars paid more and more attention to the issue of national culture and national identity. Initially, the issue of cultural identity came to Britain in the 19th century. At that time, Britain strengthened its native culture and weakened its foreign culture as a colonist. Education for all the nations emphasizes British national pride and thus distinguishes between internal and external cultures. Accepting the mainstream culture and rejecting the foreign culture, thus the problem of "cultural identity" has

*Funds: The paper is supported by the Research Project of East University of Heilongjiang. Project Name: The application of diaspora theory in English Literary Criticism. Grant Number: HDFKY200211. The paper is supported by the Research Project of East University of Heilongjiang. Project Name: A study of Doris Lessing's typical works from the perspective of ecological literature. Grant Number: HDFKY200214. The Research Project of Heilongjiang Provincial Federation of Social Sciences. Grant Number: WY2019075-C. entered the scope of British cultural research. Hall raised the issue of "cultural identity" in his article "Cultural Identity and Film Identity" in 1989, and formally proposed the concept in "Cultural Identity and Ethnic Dispersion" in 1990. Hall not only raised the issue of "identity" for the first time, but also addressed the issue of race. However, from the 1990 s to the present, "cultural identity" has not been clearly defined in scholars. Some of these scholars use a certain dimension of cultural identity to define it, for example, national identity is just cultural identity; while others think that cultural identity is described as the embodiment of people's social and cultural identity; and some scholars think that people's self-cultural identities are the embodiment of cultural identity. However, with the deepening of research, most of the researchers have been aware of the importance of defining "cultural identity".

Hall's focus on cultural identity is not only a community of social, political, and economic identities, but also a cultural inclusion, such as ideology, theoretical practice and so on. There is also the cultural identity that includes rights relationships, which can influence the formation of other identities. Hall's importance in defining cultural identity is reflected in two aspects: first, Hall embodies cultural issues from identity. He locates the main object of culture through identity. The position, composition and power relationship of the subject in the culture, as well as the dynamics 
that the subject can exercise in this position, are the important objects of Hall's research. Second, Hall views identity as a reflection of cultural issues. The structure and practice of culture are the basis and key for individuals to think about identity problems, and it is impossible to understand and explain identity problems without in-depth study of culture, nor can people better analyse the power relationship. In general, Hall's cultural identity regarded "decentration" as a research center, the same as the cultural embodiment of the later ethnic denies of Gilroy.[1] Hall believes that cultural identity reflects the original ethnic culture, ethnic culture and linguistic and religious culture. Western scholars mainly tend to define cultural identity through several cultures, which is not comprehensive, in order to build a cultural community between religion and people's imagination, rather than objectively distinguishing cultural identity. Then the two dimensions of race and nationality are considered by Hall to be the two most important aspects of cultural identity. In "Cultural Identity and the Ethnic Dispersion", Hall analyses two positions on the concept of cultural identity. In fact, Hall also constructs a third position based on and beyond the two positions - an integrated and conversational cultural identity.

\section{THE POINT OF IDENTITY AND DIFFERENCE IN CULTURAL IDENTITY}

Hall points out that the first position of cultural identity is to define cultural identity from the perspective of identity and to share the culture, which embodies the collective identity of the same true self, which is hidden in other superficial or false egos. Then people who share a history or ancestor will share this self at the same time. It can also be said that the cultural identity reflects common historical traces and shares cultural experiences that provide people, as the same race, with a stable and continuous definition in an environment of different historical changes. In this position, Hall emphasizes the "identity" and "continuity" of cultural identity. Because, first of all, Hall believes that cultural identity is due to the common enjoyment of "one" culture, and culture itself has "identity" because culture has a common source, and share a historical ancestor, with the same historical traces and cultural experience. In this way, the same nation enjoys a common overall characteristic, which is the true self mentioned by Hall, but also the most true and essential embodiment of a nation's experience. Second, Hall emphasized that culture itself is "continuous", which is due to the inheritance of culture itself. So, Hall argues that this position on cultural identity can distinguish between different cultural identities by seeing shared cultures as stable, continuous boundaries. In a cultural group, according to the meaning of shared culture to understand the world, to communicate and to exchange with the world, these are a means of expressing "cultural identity." Then through the repeated use, cultural identity is defined, accepted and then recognized, then such a "collective" cultural identity can be built successfully. Therefore, some people also think that cultural identity is used to refer to the collective self-awareness reflected in a particular group. It can also be considered a national or social enrichment of values and world views. This cultural identity is linked to the past and is the embodiment of everyone's past. This cultural identity also expresses the mapping of a culture's personal traditions and values. [2]

At the same time, Hall believes, people also need to know that the source of cultural identity in the first position is only a reflection of the past. Cultural identity is not fixed and forever unchanged in the past in a certain nature, but according to different living environment, historical and cultural influences, it changes. Hall believes that this homologous past gives the west an excuse to construct a single historical counterpart to a single identity. The west overemphasized cultural identity which is fixed by the historical and cultural, but consciously ignored the continuity of cultural identity, while at the same time to build a more "advanced" and more "civilized" cultural identity for themselves. Under the influence of the great culture of post colonialization and globalization, the scholars have to focus on what kind of culture they will become rather than always use what culture they come from to know the own cultural identity. Only in this way can people change the inherent way of thinking about the cultural identity of essentialism. That is to say, the continuity of culture itself allows us to have a common historical culture, but also it will turn with the change of historical culture. Although historical culture gives different cultural patterns and trends to different races, this trend is not always fixed and is changeable. People should determine what kind of cultural pattern it is, what kind of new cultural trends people will embody, and use it to build a new cultural identity. Rediscovering the cultural identity can be used to counter the essentialist cultural identity of the west. This idea of 
reconstructed identity can help people achieve a conscious victory in the post-colonial struggle. It can also help people re-write cultural identities that are different from those in western discourse. Through this kind of re-writing, people can reuse the way the west tries to hide to build cultural identity and locate people to reposition and build power. Hall believes that this kind of construction is crucial to rediscovering the cultural identity of the African-American community in the postcolonial movement.

Hall's second position is to acknowledge that there are some important differences beyond shared common ground, and that they come together to make up who they are today. As mentioned above, cultural identity is the result of a combination of the past built by history and the present of change first. In the second position, cultural identity is both the past and the change of future. Cultural identity is not only the embodiment of the existence of history, but also constantly changing, which cannot be fixed in a certain essential past. Only from the perspective of the future and changing views of cultural identity can people make identity and get rid of the inherent positioning, in order to make the identity of the positioning become richer and have a broader future. So, the second position places more emphasis on the differences contained in cultural identity. In this position, Hall emphasizes more on the construction of cultural identity, which is different from the western cultural identity positioning and is also different from the western discourse system level differences. Postcolonial scholars have used these differences to criticize the western view of cultural identity and the false and colonial nature of this view of identity. This kind of western not only refers to the region also the subject of western construction thought, and they build a superior cultural identity in the spirit of selfinterest, distinguishing themselves from those politically and economically superior to other regions or countries, reflecting the self-superior distinction between others. Only by recognizing the differences in cultural identity can people break the so-called cultural superiority of the colonists and the colonists, and recognize the implicit irregularity of western centralism, then realize that cultural identity in the past is only the result of the selfconstruction of the west through misinterpretation. In order to realize the broken and hidden parts of western cultural identity, these can be reconstructed by cultural identity to explore the differences.

Hall not only defines cultural identity from both common and different aspects, but also studies the third position of cultural identity definition. This position is a combination of two positions. Hall has emphasized that cultural identity is specific and is a sign of similarities and differences. In other words, Hall believes that cultural identity is formed under the public image of these two characteristics. First of all, the similarity of cultural identity is characteristic of history. Similarities in cultural identity also originate from a common culture and shared history. Sharing a culture with a group of people also produces a common and similar cultural identity - a similar reality that can be used as part of the rebuilding of cultural identity. In this way, different groups can enjoy the same position and power relationship in culture under the same historical role. At the same time, this remodelled identity of the same culture can be used to resist the rule of western colonial powers. This is Hall's theory, which explores the neglected similarities of cultural identity from a historical perspective, so that it can expose the colonial purposes of the west, thus resisting the cultural identity of nationalism and racism, and reconstructing new cultural identities and new power relations. What makes more sense in cultural identity is its differences. According to Hall, the difference refers to the difference between "other" and the difference of "continuing". These two differences are the space for political and power to survive, and only a correct understanding of these two differences can view the true purpose of western unity and its exclusive. The importance of cultural identity is not only the political power of the position in Hall's view, but also the embodiment of cultural identity under the leadership of the west. Cultural identity is formed in the communication of similarity and difference and is a complex. This exchange shows that cultural identity is a common combination of instability, homology similarity and difference. Therefore, Hall believes that cultural identity belongs to a changing category. This shows that a similar but different cultural identity is not an identity that can reflect the essence, nor can it be used as a reasonable standard for hierarchical groups.[3]

\section{THE OVERALL CHARACTER OF CULTURAL IDENTITY}

To understand Hall's theory of cultural identity deeply, people must correctly grasp the characteristics of cultural identity. First of all, cultural identity is a specific collective identity, which brings people a sense of belonging, but also the embodiment of the essence of cultural identity. 
Hall believes that cultural identity is who people are, and here "people" refers to a group of people of a particular race, ethnic group that has the same language or religious culture. It is this sense of community that has fixed the identity. But this classification only seems to be reasonable in quantity, thus hiding deception. The west uses this collectivization to distinguish cultural identity from binary opposition. Such as: mainstream and nonmainstream, civilization and non-civilization, advanced and backward and so on. All of these hide the irrationality. The rationality of collective nature that Hall emphasizes is not his purpose, and it has the instability of this distinction, but rather the collectivist that Hall criticizes has another purpose. The collective in cultural identity is a part of the cultural structure, which is passed down from generation to generation in the form of a collective. Such experiences and traces can influence people now across the limits of time and space, that's the collective, the group people know. Then the specific cultural and historical experience and traces have had the same effect on them - people have a specific production way of life, and it has a solid effect on the collective identity. In this way, people establish unique norms of behaviour, power relations, identity, and so on in the collective. However, the differences existing in this collective concept should not be excluded, and the implied meaning in a single cultural identity is conducive to the construction of the western ruling class's view of cultural identity. In this way, people can break the stable point of view in the collective view, so as to establish a new and correct view of cultural identity. The new view of cultural identity can be used to counter postcolonialism and form a new sense of resistance. In Hall's view, the behaviour of blacks in the ethnic diaspora to embody black culture in their various cultural forms is a good resistance to western centrism. This kind of collective identity constructed by the west is not stable, but also full of contradictions, which means that cultural identity in different social and cultural structures will certainly change.

Second, Hall questions the cultural identity defined by western colonialism, because it is a sense of identity and belonging formed through imagination. The traditional cultural identity view holds that sharing the same kind of history and experience with the same group should have the same cultural identity, thus forming the cultural identity and collective concept. Hall attributes this recognition to the result of imagination, which is the product of the essential culture constructed by western colonialism. This imagination constructs the imagination of the common collective through symbolism to produce practical effects, which is a kind of framework that is considered to be constructed, especially the concept of nation-state. Hall questioned the concept of nation and group, an imagination embodied in the current world's pattern and cultural identity. Cultural identity is a sense of community, and all members have such a consciousness in mind. In this way, people imagine and build a community, building a sense of belonging and security. Being able to analyse common historical experiences and groups living in the same region creates a different identity from others through imagination, and strengthens selfawareness to exclude other qualities, which is the process of the power to construct opposite relationship. Hall believes that constructing an imaginary identity is defined by one specific cultural story after another. Western colonialism ruled colonial areas by building a story that helped the colonized people. The superiority of cultural identity is also accomplished by constructing one cultural story after another. Hall tried to emphasize this and try to break this essentialism. Only by making the public clear about cultural identity and making them create identity through narrative building, people can see who they are.

Finally, cultural identity is dynamic. Hall once used this to criticize the cultural identity of western centralism, although Hall did not specify that cultural identity is dynamic in the article. Hall believes that cultural identity is changing, and as mentioned above, cultural identity belongs to both the past and the future. This change is due to the historical culture or the change of time and space, and the result is the change of the definition of cultural identity. Therefore, it is not enough to describe cultural identity by stability and continuity alone, but also to add the factors of time and space to make it a three-dimensional structure. Then any one of the four factors has changed, cultural identity will change, so history has become a direction to drive cultural identity, and cannot maintain the stability of cultural identity. Similarly, it is not comprehensive to define cultural identity by the same time and space factor, for example, different peoples in the same geographical area of the same country will also have different cultures, so that racial differences in groups lead to differences cannot be ignored. In this way, dynamic cultural identity and the western construction of a complete and stable definition of cultural identity is the complete opposite. So, the slavery, black 
identity, and so on that the west has built can only represent the past. This means that groups that share the same historical culture are not able to express their common identity in their entireties, which is simply a political tool in the west. Then, in the meaning of cultural identity flow, identity cannot be distinguished by superiority, backwardness and so on.

\section{METHODS OF CULTURAL IDENTITY CONSTRUCTION}

At the end of the 20th century, the study of the construction of cultural identity appeared in the field of sociology. In the early days, people talked about the construction of cultural identity through the difference of the social construction of boundaries, that is, through the following three ways: first, the source of culture and history; second, the subordination of social rules; third, the use of cultural boundaries in a narrow sense. In fact, either way is to tell people to distinguish themselves from him and me - disguised recognition of a relatively stable collective identity. In "The Problem of Cultural Identity", Hall mainly tends to the dynamic of cultural identity, that is, cultural identity has been in the construction state, not completed, so people can understand that cultural identity is created, not discovered. This identity is false, imagined, constructed, and people should break it. But Hall did not explicitly suggest the way cultural identity is constructed in any article, in which he suggested that the same identity constructed by history is one of the reasons for the formation of cultural identity. Because the common culture, tradition will let a group form a common identity, so the imagined common identity is formed. History is a narrative form that people understand and remember, and it provides an explanation of the origin or beginning of events. This is consistent with Hall's critical cultural identity, which is essential and consistent, and they all agree that history is a narrative form, a more self-interested way of narrative. Each country's way of recording history is subjective in its own way, and this self-interest makes it easier to emphasize the continuation of cultural identity and the specificity of history and culture. The west uses a particular history to link specific person identities, such as: the history of the west is civilized; the East is backward. In the process of constructing cultural identity, history not only produces imaginary effect in human mind, but also produces substantial results in the composition of cultural identity. Hall points out that history, like tradition, has the ability to materialize the effects of imagination. Although tradition is belonging to history, tradition is only a part of history - it comes from history and is changed by history. In fact, tradition is more of a product of society, which constructs people's cultural identity in a way that is like history. Hall stresses that cultural identity is constructed from historical narrative, and he questions the authenticity of history. Then the cultural identity with common historical experience should also be questioned. On the other way, history can also be used to highlight the hidden parts of history in an attempt to reconsecrate cultural identity. If people really want to find the source of cultural identity, they should actually look for historical means. That is, how cultural identity is described and constructed in history. [4]

Most cultural scholars agree that identity is constructed by words. In this view, Hall agrees, arguing that discourse can be both a way to dissolve the essential cultural identity and a way to rebuild the cultural identity. Then, the cultural identity constructed by different discourse systems is also different, and this kind of cultural identity is not the embodiment of the essence of identity but the relationship of identity position. So, what he reminds people is that the right to speak behind the construction of cultural identity is its political purpose. In Hall's view, discourse requires people to use a specific expression and a specific knowledge system to disseminate certain information within a certain range, and to think in this framework and to product again and again. Discourse focuses on the subject of the speaker and the subject of what rules to speak on. This rule controls how people communicate in a particular society and culture. Then, at a particular stage of history, the class with the right to speak can manipulate reality through discourse, so that some kind of distorted truth is produced. So Hall used these rules of discourse to remind people that the cultural identity of race is not a universal embodiment of nature, but rather a way that western class constructed and defined by discourse according to its own wishes. So, the hidden parts of the truth that are obscured by the western classes really should be restored. Hall systematically criticized the construction of cultural identity by the western class. He pointed out that the west is first and foremost a social or social development degree, and the west is also the product of the construction of historical discourse. Second, the west also contains the relationship of intellectual power. People would consider non-western regions to be 
representatives of underdeveloped or deindustrialized regions. Hall provides an opportunity for non-western cultures to reconstruct cultural identity by exploring the discourse construction of cultural identity.

After World War II, another noun related to cultural identity appeared in the eyes of researchers — politics of difference. Hall's statement about the politics of difference appeared in an article at the end of the 1990s, and he believed that different forms of politics should also be thought again when it comes to rethinking identity. Because politics is constantly changing in the international form, the effects of globalization are two-faced. Hall believes that globalization brings about a diverse and changing world, and that is difference. At the same time, globalization also has a confrontation situation. Globalization provided an opportunity for exchange and consultation among cultures, which needed to find the means of consultation to solve cultural problems through communication rather than confrontation. These problems are differences, and globalization is the provider of differences and the spreader of differences. This is what Hall calls a world of difference, a world of recognition of diverse identities. [5]

\section{REFLECTIONS ON HALL'S THEORY OF CULTURAL IDENTITY}

Hall has spent his whole life searching for the end of cultural identity, and what will be the future of cultural identity? Hall has never set a definitive answer to a question, but in terms of the future outcome of cultural identity, Hall has made it clear that his answer is diaspora status. That is to say, Hall believes that the ideal state of cultural identity theory is the shape of ethnic diaspora identity. The diaspora is in the context of globalization and cosmism. Hall argues that there is a difference between globalization and cosmopolitanism. He prefers to analyse identity from a global perspective. Hall believes that globalization is a system of mixed contradictions, which create new space for new forms. Globalization itself has a combined force that combines the elements of separation as if it were said: part must unite, part must unite. In the process of integration, the contradictory community brought about by globalization provides opportunities for difference and change. Unlike globalization, cosmism is more confusing in Hall's view, hiding some disharmonious contradictions and real unequal power relations. In Hall's view, cosmopolitanism is divided between upward and downward cosmopolitanism. Upward globalism is the movement of global entrepreneurs in accordance with the power of multinational enterprises and global investment and capital. In the process, power and resources became the main dominant forces. This trend, which has directed both advantages and high-quality resources to more developed countries, offers an opportunity for capitalism to now dominate. At the same time, this trend also brings some technology and experience to the less developed countries, but also the opportunity for capitalism to play homogenization. These are all things Hall opposes. In downward capitalism, people are forced to leave their homes and integrate into different cultures and countries. This flow breaks down geographical boundaries, crosses national boundaries and promotes the integration and exchange of different cultures. These are the differences. Among the differences, Hall tends to embody the unequal theory of globalization. The phenomenon of people being forced to leave their homes in downward cosmism is exactly the ethnic diaspora proposed by Hall. This ethnic Hall calls the neo-diaspora. There has always been a cultural nationalist tendency in the hearts of the old ethnic diaspora. This is an old mode of thinking, which is embodied in the affirmation of the concept of identity. Communities with this identity are eager to return home in search of a source of culture. Such ethnic diaspora is closed, choosing to be separated from their hearts and to abandon their old identities and integrate into the new country. In such cases, the ethnic diaspora clings to its old identity, rejects new cultures and histories and is not integrated into them. Hall sees the new ethnic diaspora as an ethnic group with an open mind. Their ethnic diaspora can create new identities, and they insist that differences and at the same time they also persist it. New communities can accept transformation, integration and change while preserving their unique culture. The new ethnic diaspora, who have gone through downward cosmism, is the future state of their ideal cultural identity, and they are able to preserve themselves while creating new identities of their own.

Hall's study of cultural identity begins with breaking the definition of existing cultural identity, and he talks about breaking and multiplicity introducing cultural identity, which can help cultural identity to get rid of the binary model of non-black and white. While breaking down, Hall also focused on rebuilding. In concept, Hall breaks 
the essentialism to limit the cultural identity and constructs a new dynamic cultural identity view. This is a new identity that is more diverse and inclusive. This is reflected in his break with the old ethnic diaspora model to build a mixed new ethnic diaspora model.

\section{THE COMBINATION OF CULTURAL IDENTITY THEORY AND CROSS-CULTURAL TEACHING}

In cross-cultural learning, learning a language is much simpler to use; but to learn a language well, you must understand the culture it represents. Culture is the most important in college English teaching, and understanding foreign culture is also the key to the consciousness of local culture. So, this identity has also been a difficult point for teaching. Cultural identity theory is the theory that people re-identify with their own identity. While studying this theory, the author also hopes to make use of it in college English teaching, so that students can better learn English culture and language. In college English teaching, most students can write sentences with correct grammar. But these "non-native" English sentences are sometimes unable to communicate effectively due to a lack of cultural identity. Cultural identity is the sense of cultural belonging and cultural group that an individual feels from himself. It is based on the culture to which the language is used. Cultural identity involves social values, religious beliefs, customs, language and art etc. Increasingly frequent international cooperation brings countries and countries closer together and provides an opportunity for different cultures to communicate and interact closely. In this process, people can not only in-depth understand of their knowledge, of their local culture and foreign culture, but also face a crisis of cultural identity, so school education should strengthen students' cultural awareness and will, establish cross-cultural exchange awareness, improve their own cultural identity to protect the survival and development of local culture rights. Because cultural identity is based on the cognitive nature of human ascension, it has a decisive influence on human language and value orientation. It is also defined by the consensus and recognition of human culture. On this basis, cultural identity often provides pragmatic principles to guide specific cross-cultural communication behaviour relationships. ${ }^{[6]}$
In foreign language teaching, College English teachers should consciously compare Chinese culture with western culture, especially introduce Chinese culture. It can make college students fully understand the excellent Chinese culture and stimulate students' sense of national pride. College English teachers should guide students to learn to express Chinese culture in English and carry forward the essence of international exchanges of traditional Chinese culture. At the same time, college English teaching should help students learn more about the world cultural heritage. Human acceptance of indigenous culture is often in an unconscious state. Because of the lack of conscious guidance and stimulation, people hardly reflect on the culture on which they depend. Even if people occasionally have similar thoughts, they are bewildered by the cultural phenomenon of confusion and disorder and do not know how to deal with it. The purpose of cultural teaching is to strengthen the understanding of university students' knowledge of their native culture, to prevent students from being locked into the ideology of national centrism, to help them rationally understand their value orientation and mode of action, and then to help them develop open and flexible thinking patterns. Having a cultural awareness requires going through a difficult process. Understanding your culture is a prerequisite. Then understand that a multicultural environment can position itself in a multi-level cultural world. People need to adapt consciously the existence of cultural diversity, constantly communicating with different cultures, and then creating a set of social order and code to promote harmonious development and coexistence.

\section{CONCLUSION}

Although Hall did not propose the theory of cultural identity system in any article, in his nearly 30 years of literature people can find his continuous and rich process of this theory. Therefore, this paper has also carried out a rough study on the understanding of the theory of ethnic diaspora and Hall's theory of cultural identity. Hall's research on the problem of cultural identity is instructive, as it can be seen from the solution of the real problems of British society, and it also provides a theoretical basis for the study of China's construction of cultural identity in a foreign country. Hall's study of cultural identity is actually a study of different ethnic groups, a wake-up call to their selfconsciousness, and he hopes that his research will enable each ethnic group to clearly understand the 
complexity of society and the political purposes of society, so as to become a new group that can accept the new world without giving up on itself. Finally, Hall put forward in the reality analysis, the world must develop into a new world of diversity. Cultural mix is not only a mix of ethnic population, but a mixed impact of culture and history process. This new world will create a new mixed, open and inclusive cultural identity. In an era of globalization, people must recognize the identity and recognize the mix and differences of identity in order to eliminate western hegemony. This recognition of the new world, identity affirmation can also be applied to cross-cultural teaching, so that students can understand the importance of Chinese cross-cultural learning.

The continuous study of identity culture and the search for the re-construction of cultural identity make Hall's research have epoch-making significance. By recognizing the differences, people could let the differences coexist in order to achieve the identity of the subject of equality and freedom of the new world.

\section{AUTHORS' CONTRIBUTIONS}

Bo Yang wrote the manuscript, Dan Zhao contributed to revising and $\mathrm{Lu}$ Liu contributed to editing.

\section{REFERENCES}

[1] Gilroy, P. The Black Atlantic: Modernity and Double Consciousness [M]. Verso, 1993.

[2] Hall, S. Critcher, C.\& Jefferson, T.et al. Policing the Crisis: Mugging, the State and Law and Order [M]. New York: Macmillan Press Ltd, 1982.

[3] Hall, S. et al. Culture, Media, Language: Working Papers in Cultural Studies (19721979) [M]. London: Hutchinson, 1980.

[4] Hall, S. The Empire Strikes Back [M]. London: Routledge, 2004.

[5] Hall, S. The Fateful Triangle: Race, Ethnicity, Nation [M]. London: Harvard University Press, 2017.

[6] Barker, C. Cultural Studies: Theory and Practice [M]. London: Sage, 2003. 